\title{
CONCORDÂNCIA DE GÊNERO VARIÁVEL EM PORTUGUÊS: APROXIMAÇÕES ENTRE VARIEDADES AFRICANAS E AFRO-BRASILEIRA
}

\author{
Ana Lívia AGOSTINHO ${ }^{1,2}$ \\ Luana LAMBERTI ${ }^{3}$ \\ Eduardo Ferreira dos SANTOS ${ }^{4}$
}

\section{DOI: http://dx.doi.org/10.21165/gel.v18i3.3276}

Resumo: Este trabalho objetiva apresentar uma breve descrição comparativa dos aspectos da não concordância de gênero do sintagma nominal, atestados de forma semelhante em três variedades africanas da língua portuguesa, a saber: o português falado em Angola, especificamente do Município do Libolo; o português falado em São Tomé e Príncipe; e o português falado em Helvécia, na Bahia, Brasil. Trabalhos sobre a concordância nominal para as variedades brasileira e europeia do português apontaram, por exemplo, para uma regra variável para a primeira e categórica para esta última (BRANDÃO; VIEIRA, 2012; BRANDÃO, 2018). Alguns estudos sobre as variedades africanas e afro-brasileira do português já destacam as descrições e análises acerca da concordância nominal em Angola, Moçambique, São Tomé e Príncipe, Guiné-Bissau e Helvécia, Brasil (INVERNO 2004, 2009; PETTER, 2009; LUCCHESI; BAXTER; RIBEIRO, 2009; FIGUEIREDO, 2010; SEDRINS; SILVA, 2017; entre outros). A partir da descrição e análise de dados coletados em trabalho de campo, proporemos aproximações entre as três referidas variedades e os possíveis fatores sociais que possam influenciar a não realização dessa concordância nominal, principalmente no que concerne ao contato linguístico, contexto sociohistórico e aprendizado do português como L2 ou como L1 a partir de um modelo de L2.

Palavras-chave: Concordância Nominal. Concordância de Gênero. Português de Angola. Português de São Tomé e Príncipe. Português de Helvécia. Contato Linguístico.

\footnotetext{
1Os autores estão dispostos em ordem alfabética uma vez que contribuíram igualmente para o desenvolvimento e escrita do texto. Assim, a ordem apresentada não reflete ordem de autoria.

2 Universidade Federal de Santa Catarina (UFSC), Florianópolis, Santa Catarina, Brasil; a.agostinho@ufsc.br; http://orcid.org/0000-0002-2395-4961

3 Ohio State University (OSU), Columbus, Ohio, Estados Unidos da América; luanalamberti@gmail.com; http://orcid.org/0000-0001-9060-2715

4 Universidade da Integração Internacional da Lusofonia Afro-Brasileira (UNILAB), São Francisco do Conde, Bahia,Brasil; eduardo@unilab.edu.br; http://orcid.org/0000-0001-9127-9235
} 
- Concordância de gênero variável em Português: aproximações entre variedades africanas e afro-brasileira

\section{VARIABLE GENDER AGREEMENT IN PORTUGUESE: APPROXIMATIONS BETWEEN AFRICAN AND AFRO- BRAZILIAN VARIETIES}

Abstract: This article presents a brief description of the aspects of gender non-agreement in the noun phrase that were similarly attested in three African varieties of Portuguese, knowingly: Angolan Portuguese, specifically spoken in the municipality of Libolo; São Tomé and Príncipe Portuguese; and Helvécia Afro-Brazilian Portuguese, spoken in Bahia, Brazil. Previous works on nominal agreement of Brazilian and European Portuguese pointed to a variable rule for the former and a categorical rule for the latter (BRANDÃO; VIEIRA, 2012; BRANDÃO, 2018). Some studies on the African and Afro-Brazilian Portuguese varieties have highlighted descriptions and analyzes of nominal agreement in Angola, Mozambique, São Tomé and Príncipe, Guinea-Bissau, and Helvécia (WINTER, 2004, 2009; PETTER, 2009; LUCCHESI; BAXTER; RIBEIRO, 2009; FIGUEIREDO, 2010; SEDRINS, SILVA, 2017, among others). From the description and analysis of data that was collected in fieldwork, we propose approximations between the three varieties and the possible social factors that can influence their nominal agreement, especially regarding language contact, the sociohistorical context of each community, and the acquisition of Portuguese as an L2 or as an L1 from an L2 template.

Keywords: Nominal Agreement. Gender Agreement. Angolan Portuguese. São Tomé and Príncipe Portuguese. Helvécia Portuguese. Language Contact.

\section{Introdução}

O objetivo deste trabalho é apresentar uma descrição comparativa preliminar dos aspectos da não concordância de gênero do sintagma nominal em três variedades de contato da língua portuguesa, a partir da descrição de dados semelhantes. As variedades estudadas são: o português falado em Angola, especificamente do Município do Libolo; o português falado em São Tomé e Príncipe e o português falado em Helvécia, na Bahia, Brasil.

Nos estudos de descrição e análise da língua portuguesa, nos últimos anos, diversos trabalhos apontaram as diferenças e aproximações nas gramáticas do português brasileiro (doravante, PB) e do português europeu (doravante, PE), como no quadro dos pronomes, no uso das preposições, na ordem dos constituintes, na interface sintaxe/discurso etc. Para o fenômeno da concordância nominal, também há trabalhos que buscaram descrever e analisá-lo nessas variedades. 
Seguindo Lucchesi (2009), as categorias gramaticais de número e gênero associamse, no plano semântico-lexical, essencialmente ao nome e se estendem, no plano sintático, através do mecanismo da concordância, aos termos que lhe determinam o sentido: o artigo, o adjetivo, o pronome e o numeral. Assim, o sintagma nominal (doravante, SN) é uma construção sintática em que o nome é o elemento nuclear.

Em relação à concordância de gênero, a sua indicação mórfica, na maioria das vezes, é feita exclusivamente através da concordância, na medida em que a maioria dos nomes não porta nenhuma marca formal de gênero (LUCCHESI, 2009). Vejamos o SN abaixo:

$$
\text { [as tribos indígenas] }
$$

Em (1) o núcleo tribos tem seu gênero feminino depreendido apenas pela morfologia de feminino do artigo e do adjetivo, atestando que a análise da categoria gramatical do gênero compreende, por um lado, a sua estruturação no léxico da língua e, por outro lado, a sua manifestação na estrutura sintagmática da sentença (LUCCHESI, 2009).

$\mathrm{Na}$ língua portuguesa, o gênero compreende apenas dois valores, masculino e feminino, e é um índice gramatical sem qualquer implicação semântica e também uma categoria flexional para toda uma classe de nomes. No plano referencial, está relacionado à distinção entre os sexos dos seres. Para as classes dos nomes de gênero único, é difícil encontrar um padrão regular na indicação formal do gênero (LUCCHESI, 2009).

Lucchesi (2009) chama a atenção para o fato de a variação na concordância de gênero não ser comum entre as variedades rurais do português - e consequentemente de outras variedades mais urbanas. Mas destaca, também, que só se registra um nível significativo de variação na concordância de gênero em certas comunidades rurais que passaram por um amplo e profundo contato linguístico em sua história, como o português afro-brasileiro de Helvécia (LUCCHESI, 2009), - dados (13) e (15), renumerados:

$$
\text { Ele era [uma pessoa] muito querido]. }
$$$$
\text { se tirá [o [certidão] de óbito do meu pai] }
$$

Em (2), o núcleo do SN pessoa apresenta concordância com seu determinante uma. No entanto, a mesma concordância não se dá com o adjetivo querido, manifestado, no dado, com o gênero masculino. Em (3), o núcleo do SN certidão, gênero feminino, não concorda com seu determinante masculino $o$.

Essa variação também pode ser encontrada em variedades vernáculas e de português como segunda língua, como as variedades africanas, que assim como o PB e algumas de suas variedades, estão imersas em um ambiente plurilíngue e de intenso 
- Concordância de gênero variável em Português: aproximações entre variedades africanas e afro-brasileira

contato linguístico. Essa aproximação levou ao que Petter (2008) considerou como um continuum afro-brasileiro, fazendo com que o entendimento mútuo das variedades africanas e brasileira do português, e suas especificidades, nos auxiliaria em apontar o que, de fato, nos aproxima (ou distancia).

Para as variedades africanas de português, Figueiredo (2009) apresenta concordância variável de gênero no português de Almoxarife, São Tomé e Príncipe, uma variedade reestruturada cujo substrato é o santome (ou forro, ver 2.2). Brandão (2018) elenca uma série de trabalhos que contemplaram a concordância nominal em São Tomé, Moçambique, Cabo Verde e Angola. Para o português falado em Guiné-Bissau (doravante, PGB), Castro (2013, apud SEDRINS; SILVA, 2017, - dados (3), remunerados) indica que a distinção entre o gênero masculino e feminino é quase inexistente, como vemos em (4):
a. o meu irmã
b. meu mãe
c. ele tem três filho fêmea

Se olharmos para este fenômeno em uma perspectiva linguística ampla, a variação da concordância de gênero é comum em variedades do espanhol que foram formadas em um contexto de intenso contato linguístico, como o espanhol andino e o falado na Província de Corrientes na Argentina (PINTA, 2021, no prelo). No último cenário, esta variedade do espanhol, que mantém um contato histórico com o Guarani na região, apresenta um desfavorecimento da concordância de gênero em contextos com modificadores não adjacentes ao núcleo do SN (PINTA, 2021, no prelo). Este e outros estudos sobre o tema (SÁNCHEZ, 1996; LIPSKI, 2006) oferecem uma contribuição importante sobre o papel do contato na variação e mudança linguística que afetam o sistema de marcação de gênero.

Assim, para além das questões de estruturação regular e básica, precisamos considerar que "em sociedades multilíngues em que se tem desenvolvido uma segunda língua veicular e/ou oficial pós-colonial como L2 [...] há amplas evidências da influência das línguas maternas originais dessas comunidades sobre as emergentes L2/L1" (BAXTER, 2009), como é o caso de Angola, em que temos, para além do português, algumas línguas do grupo bantu, como o quimbundo, falado no Município do Libolo; o caso de São Tomé e Príncipe, que convive com quatro línguas crioulas, e o caso do português afro-brasileiro de Helvécia que foi formado no século XIX através de um intenso contato linguístico entre línguas do oeste africano (majoritariamente o lorubá e diversas línguas do grupo bantu) e o português. 
Nosso trabalho, portanto, apresentará os aspectos sociolinguísticos de Angola, São Tomé e Príncipe (doravante, STP) e Bahia, destacando, respectivamente, o Município do Libolo, São Tomé e Príncipe e a comunidade de Helvécia. Consideramos fundamental a contextualização sociolinguística destas três localidades pelo papel central que o contexto social exerce na formação linguística de uma determinada variedade. Diversos autores no campo da sociolinguística (THOMASON; KAUFMAN, 1988; WINFORD, 2013) destacam a importância deste tipo de contextualização, quando estudamos fenômenos que envolvem um contato linguístico intenso. Sendo assim, destacamos esses aspectos para estabelecer uma fundamentação que será relevante para a discussão do fenômeno de nosso interesse: a concordância de gênero.

Em seguida, apresentaremos, de maneira breve, um panorama dos estudos da concordância do SN no PB, PE e algumas variedades africanas da língua portuguesa e a abordagem do fenômeno da concordância no SN em relação ao gênero no português do Libolo (PLB), do português de São Tomé e Príncipe (PSTP) e do português de Helvécia (HEL). Encerramos nosso artigo com as considerações finais e as referências bibliográficas.

\section{Contextualizando a língua portuguesa em Angola}

Angola é um país localizado na região ocidental da África Austral e suas fronteiras são ao norte/nordeste, com a República Democrática do Congo, a leste, com a República da Zâmbia e, ao sul, com a República da Namíbia, sendo banhado pelo Oceano Atlântico, a oeste.

O último CENSO realizado no país em 2014 mostrou que a população angolana é de 25.789.024 habitantes, distribuídos em 18 Províncias conforme sua divisão políticoadministrativa, sendo a Província de Luanda, que abriga a capital do país de mesmo nome, a mais habitada, com 6.945.386 de residentes.

No que diz respeito aos aspectos linguísticos, o mesmo CENSO aponta que predomina, em números quantitativos, línguas pertencentes ao grupo bantu, como umbundo, quicongo, quimbundo, chokwe etc. No entanto, a língua, em número percentual, com a maior quantidade de falantes é o português, correspondendo a $71 \%$ da população. Essa elevada percentagem pode ser explicada, principalmente, em razão de a língua portuguesa, em Angola, ter estatuto de única língua oficial do país, impactando nas esferas econômico-sociais, culturais e educacionais. 
- Concordância de gênero variável em Português: aproximações entre variedades africanas e afro-brasileira

Gráfico 1. Línguas mais faladas nas residências angolanas



Fonte: CENSO (2014) .

A presença da língua portuguesa em Angola, em um espaço geográfico plurilíngue, predominantemente bantu, remonta ao processo de colonização que Portugal, dentre outros países, empreendeu no contexto colonial e escravista, em meados do século XV. No território que hoje equivale à atual configuração político-administrativa angolana, os portugueses iniciaram sua invasão no período de 1482 a 1484, liderados por Diogo Cão. Os povos, que ali já estavam, formavam o que se reconhece como uma das primeiras grandes unidades políticas formadas no século XIII, após as migrações bantu: a unidade política do Reino do Congo, mais as regiões de Ndongo e Matamba (BIRMINGHAM, 1974). Essa grande unidade política possuía línguas e culturas próprias e seus povos resistiram até onde foi possível para que fossem mantidas suas hegemonias sociopolítica e econômica.

Neste período colonial, não foram apenas as relações comerciais que motivaram a presença portuguesa em Angola, mas também o uso do grande contingente populacional para fins da escravidão, servindo aos interesses coloniais portugueses como abastecimento de mão de obra escravizada para a Metrópole e demais colônias portuguesas, intensificando-se, assim, uma diplomacia e contato entre portugueses e a população angolana, com os primeiros influenciando, inclusive, os costumes religiosos e linguísticos (SANTOS, 2018).

5 https://bit.ly/3stmmPc 
No século XIX, com a pressão e imposição inglesas pelo fim da escravização, extinta oficialmente em 1878 (PELISSIER, 1997), os portugueses se voltam para o desenvolvimento de suas colônias africanas, inclusive Angola, agora tomadas como Províncias Ultramarinas, com a emigração dos portugueses e a proposta de disseminação da civilização e cultura europeias. Surge, portanto, uma dinâmica social pautada, entre outros fatores, pela questão sociolinguística, com uma hierarquização da população entre colonizadores e colonizados, implicando uma divisão entre assimilados e indígenas (HERNANDEZ, 2008), em que o domínio da língua portuguesa é um dos pré-requisitos para pertencimento dessa nova condição social. Já na segunda metade do século XX, o aumento do número de colonos e o desenvolvimento de uma comunidade urbana propiciam a generalização da língua portuguesa, com as línguas nacionais sendo consideradas empecilhos para uma unidade nacional (MIGUEL, 2003).

Para Miguel (2008), o contato da língua portuguesa com as diferentes línguas angolanas deve ser considerado um fator de marcação da identidade linguística de Angola como uma nova variedade de português distinta da norma europeia.

\section{O Município do Libolo}

O Libolo está localizado no interior de Angola, na Província Cuanza Sul - capital Sumbe - e possui cerca de 87.244 habitantes (FIGUEIREDO, 2018) distribuídos em quatro Comunas: Calulo (sede do Município), Munenga, Quissongo e Cabuta.

A maior parte do contingente populacional angolano pertence ao grupo linguístico bantu, repartido em grupos linguísticos distintos em termos numéricos e que caracterizam as relações entre etnia, língua e cultura, delimitando os agrupamentos etnolinguísticos e explicitando o cenário linguístico do país (REDINHA, 2009).

Conforme aponta Figueiredo (2018), o Libolo é uma região ambundo onde se encontram falantes do quimbundo língua materna, variedade libolo, além da variedade chamada de ngoya por alguns habitantes das comunas de Calulo e Quissongo. O Município é uma zona de confluência de falantes de quimbundo kissama e kibala, além de falantes da língua songo, e está nas limitações de regiões ovimbundo, com falantes da língua umbundo (FIGUEIREDO, 2018). 
- Concordância de gênero variável em Português: aproximações entre variedades africanas e afro-brasileira

Mapa 1. Limites fronteiriços da língua quimbundo e o Município do Libolo

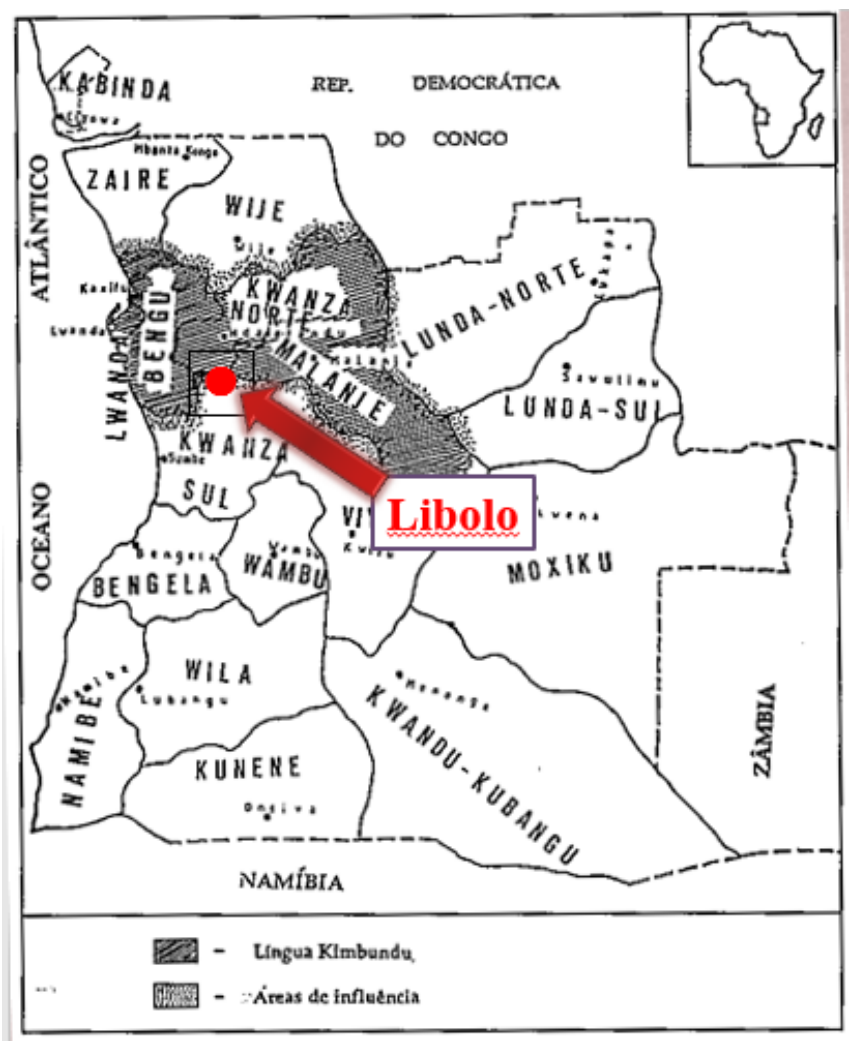

Fonte: Figueiredo e Santos (2013) - adaptado de Mingas (2000).

A presença da língua portuguesa no Município também remonta ao período colonial e à chegada dos portugueses em terras angolanas. Vale destacar, neste caso, que o tipo de colonização territorial dos portugueses, em Angola, privilegiou, a princípio, as zonas litorâneas e suas proximidades, ficando o interior do país quase inexplorado em meados do século XIX e início do século XX. Para Figueiredo (2018), esse fato propiciou condições para uma diglossia linguística no país: de um lado, uma elite afro-portuguesa bilíngue, restrita aos centros urbanos e ao uso do português nestes espaços; e de outro lado, uma grande parcela de falantes monolíngues nas mais diversas línguas maternas angolanas e habitantes das zonas rurais e interioranas do país. A ocupação do Libolo inicia-se, de forma sistemática, a partir de 1840, culminando na instalação da Missão Católica de Santo Antonio de Calulo, em 1893.

Embora se tenham registros de confrontos entre nativos e forças militares portuguesas para a ocupação dos territórios libolenses, com a consequente pacificação da região em 1918, durante o período que se desenrolou a independência de Angola (1975), o Município do Libolo viveu um certo período de paz (FIGUEIREDO; OLIVEIRA, 
2013). No entanto, o Município foi alvo de algumas incursões de tropas dos três grupos nacionalistas que, após combater o colonialismo português, demandavam o controle do país. Com esses ataques, "as estruturas do Município colapsaram e o isolamento das Comunas administrativas acentuou-se, extinguindo-se também o seu sistema educacional, rodoviário e de comunicação" (FIGUEIREDO; OLIVEIRA, 2013, p. 121). Para Figueiredo (2018), estas particularidades propiciaram para que no Libolo tivéssemos além da defesa e preservação de ideologias autóctones, também a conservação de tradições socioculturais milenares e de marcas linguísticas específicas dos seus falantes, como traços morfossintáticos da L1 quimbundo incorporados no português falado no Município.

\section{São Tomé e Príncipe}

As ilhas do Golfo da Guiné eram desabitadas antes da chegada dos portugueses no final do século XV. Segundo Cardoso (2007), as ilhas de São Tomé e Príncipe teriam sido descobertas pelos navegadores portugueses João de Santarém e Pedro Escobar, chegando a São Tomé em 21 de dezembro de 1470 e ao Príncipe em 17 de janeiro de 1471. Segundo Araujo et al. (2013), a data exata da chegada de europeus à Ilha de Ano Bom é controversa. O ano da descoberta de Ano Bom é situado entre 1471 e 1501 por diferentes autores (ARAUJO et al., 2013).

Há quatrolínguas crioulas autóctones e geneticamente relacionadas (SCHUCHARDT, 1889; GÜNTHER, 1973; FERRAZ, 1979; HAGEMEIJER, 2011; ARAUJO et al., 2013; BANDEIRA, 2017, entre outros) no Golfo da Guiné: santome (ou forro), angolar, lung'le e fa d'Ambô. As duas primeiras são faladas na Ilha de São Tomé e Príncipe, a terceira na Ilha do Príncipe e a última é falada nas ilhas de Ano Bom e Bioko, na Guiné Equatorial. As quatro línguas, embora aparentadas, são atualmente ininteligíveis entre si. O kabuverdianu, nativo de Cabo Verde, também é falado no Príncipe. 
- Concordância de gênero variável em Português: aproximações entre variedades africanas e afro-brasileira

Mapa 2. O Golfo da Guiné

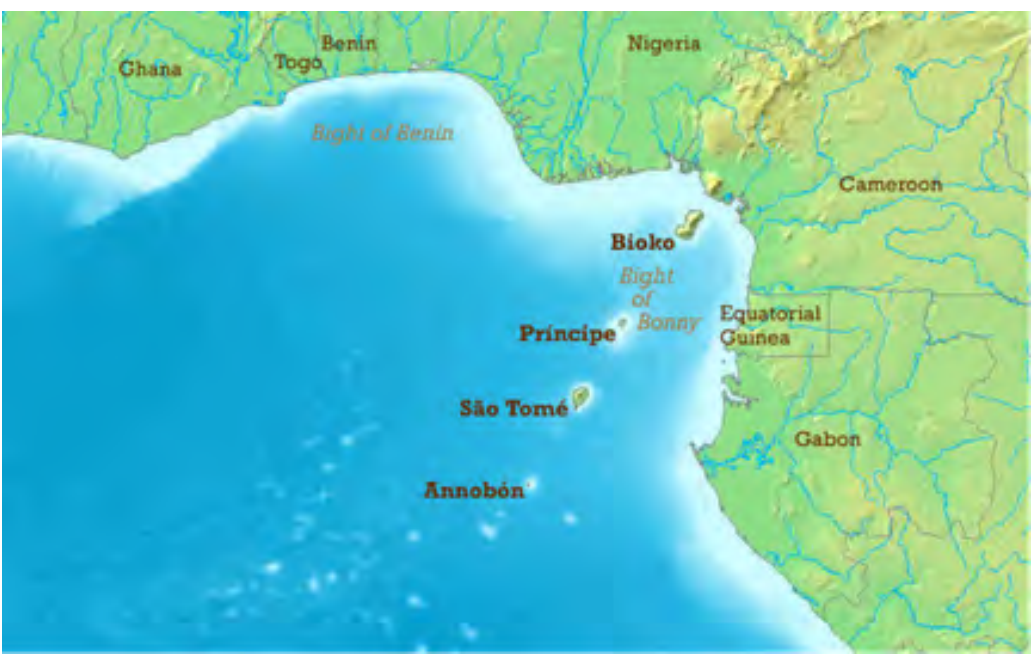

Fonte: https://commons.wikimedia.org/wiki/File:Gulf_of_Guinea_(English).jpg.

O povoamento de São Tomé por portugueses, outros europeus e escravizados se deu através de uma ordem da coroa portuguesa e começou a ser contínuo a partir de 1493 (CARDOSO, 2007). A Ilha de São Tomé foi a primeira a ser povoada, entre os anos 1480 e 1493. As ilhas do Príncipe e de Ano Bom foram povoadas a partir de São Tomé por portugueses e escravizados africanos oriundos de São Tomé a partir de 1500 e de 1503, respectivamente. A Ilha de São Tomé foi inicialmente povoada por escravizados principalmente do Delta do Níger, onde são faladas línguas edóides, e, mais tarde, principalmente do Congo e de Angola (CALDEIRA, 2008, 2013; SEIBERT, 2013, 2014), onde são faladas línguas do grupo Bantu. Posteriormente, foram transplantados diretamente para a Ilha do Príncipe um contingente de escravizados oriundos da região Delta do Níger, local onde se falavam línguas do grupo Edo. Ao mesmo tempo, o Príncipe recebeu um número pequeno de prisioneiros de regiões Bantu, ao contrário de São Tomé (HAGEMEIJER, 2011), após a separação dos falantes de PGG. Assim, o principal substrato africano do PGG são as línguas do Delta do Níger, particularmente as línguas edóides. As línguas do grupo Bantu tiveram um papel secundário (HAGEMEIJER, 2011; ver também LADHAMS, 2012; AGOSTINHO; ARAUJO; SANTOS, 2019).

Neste cenário multilíngue, do contato entre os colonos e os escravizados, surge uma língua emergencial, que, expandida, deu origem ao Protocrioulo do Golfo da Guiné (doravante PGG) (cf. FERRAZ, 1979; HAGEMEIJER, 2011; BANDEIRA, 2017). Após a formação do PGG, durante o início até meados do século XVI, deu-se início à separação geográfica de seus falantes (cf. BANDEIRA, 2017) que contribuiu para a especiação que resultou nas quatro línguas faladas hoje. Nesse sentido, consideramos que os escravizados levados de São Tomé ao Príncipe já fossem falantes do PGG (BANDEIRA, 2017). 
A segunda fase de povoamento de STP, a partir do século XIX, trouxe trabalhadores contratados de outros países africanos, sobretudo de Cabo Verde (HAGEMEIJER, 2009), o que contribuiu ainda mais para o plurilinguismo dessa sociedade. Posteriormente, outros grupos de falantes de kabuverdianu foram levados ao Príncipe devido à escassez de mão de obra local, relacionada a uma epidemia de doença do sono na ilha durante o início do século XX (MAURER, 2009).

Os dados referentes ao número de habitantes de STP são, muitas vezes, díspares. Assim, a população de São Tomé e Príncipe pode variar de 100 mil a 200 mil habitantes, dependendo da fonte. A população da Ilha do Príncipe varia entre 6 mil a 13 mil habitantes. Segundo Cardoso (2007), a população de São Tomé em 2000 era de 133.624 habitantes, enquanto a do Príncipe era de 6.036, somando 139.660 habitantes para todo o arquipélago.

O censo de 2012 não oferece dados sobre o bilinguismo ou o multilinguismo, porém afirma que cerca de $98,9 \%$ da população são-tomense fala o português (sem defini-lo como primeira língua, L1, ou como segunda língua, L2). Um total de 72,4\% falaria o santome e 2,4\%, o lung'le. As línguas restantes (angolar, kabuverdianu, francês, inglês, entre outras) formam o grupo 'outras línguas', totalizando 12,8\%. Na tabela abaixo, podemos observar o número de falantes para cada língua registrado nos censos dos últimos anos. Segundo Santiago e Agostinho (2020), o censo de 2019 não apresenta dados sobre as línguas faladas no arquipélago. É válido ressaltar, porém, que esse número não corresponde necessariamente à realidade. Dados obtidos em trabalho de campo com o lung'le, por exemplo, atestam para um número de falantes de 20 a 200 pessoas, por exemplo (AGOSTINHO, 2015, 2016, 2019; MAURER, 2009).

Tabela 1. Distribuição por número de falantes por língua

\begin{tabular}{c|c|c|c|c|c|c}
\hline Censo & Português & Santome & Lung'le & Angolar & Kabuverdianu & Outras \\
\hline $\mathbf{1 9 8 1}$ & 60.519 & 54.387 & 1.533 & - & - & 8.180 \\
\hline $\mathbf{1 9 9 1}$ & 94.907 & 69.999 & 1.558 & - & - & 12.781 \\
\hline $\mathbf{2 0 0 1}$ & 136.085 & 99.621 & 3.302 & - & - & 17.612 \\
\hline $\mathbf{2 0 1 2}$ & 170.309 & 62.889 & 1.760 & 1.217 & 14.725 & 4.224 \\
\hline
\end{tabular}

Fonte: Balduino (2018)

O português, língua oficial desde a independência em 1975, é a língua mais falada em São Tomé e Príncipe. Seu crescimento está atrelado a políticas linguísticas e educacionais desde a independência do país, em 1975, e ao abandono das línguas nacionais. É possível observar nos dados dos censos que o número de falantes de português praticamente 
- Concordância de gênero variável em Português: aproximações entre variedades africanas e afro-brasileira

triplicou em um intervalo de 30 anos. A língua é empregada em todas as comunicações de Estado, na educação e na mídia. Segundo Araujo e Agostinho (2010), a norma portuguesa europeia é ensinada nas escolas e dominá-la é o objetivo do sistema escolar. Segundo os autores, o uso generalizado do português na mídia, na escolarização, no governo, bem como o uso das variedades reestruturadas que convivem com variedades próximas da 'norma' europeia não podem ser descartados do contexto sociolinguístico de São Tomé e Príncipe.

O santome, que tem se tornado a língua crioula mais falada mesmo pelos outros grupos minoritários, é cada vez menos aprendido como língua materna, papel desempenhado pelo português. O angolar é falado na Ilha de São Tomé, majoritariamente no distrito de Caué.

O lung'le é falado majoritariamente na Ilha do Príncipe. O número de falantes nativos, dependendo da fonte, varia de 20 (MAURER, 2009) a 1300. Valkhoff (1966) mencionou ter tido dificuldade para encontrar falantes nativos dessa língua já em 1958. Günther (1973), por sua vez, aponta que o lung'le estaria em processo de extinção, sendo substituído pelo santome e pelo português. Segundo Araujo e Agostinho (2010), a mídia e a escolarização (fenômenos pós-independência) dão ao português um prestígio que não pode ser rivalizado, o que implica um abandono crescente das línguas nacionais.

Segundo Agostinho et al. (2016), de acordo com a tipologia de Crystal (2000), o lung'le pode ser categorizado como uma língua ameaçada, devido à ausência de crianças a adquirindo como primeira língua, à atitude da comunidade que não tem buscado, majoritariamente, fazer uso regular do lung'le em todas as circunstâncias sociais, e, por fim, ao nível de impacto de outras línguas, principalmente o português, língua oficial e mais utilizada em todas as esferas sociais, e o kabuverdianu, já que há muitos falantes descendentes dos trabalhadores contratados que chegaram na ilha no final do século XIX e começo do XX.

Atualmente, existem maisfalantes nativos dekabuverdianu no Príncipe doquefalantes nativos de lung'le, havendo, inclusive, inúmeros falantes monolíngues (AGOSTINHO, 2015). Maurer (2009) afirma que, embora o Censo de 2001 tenha apontado que 16,3\% da população da Ilha do Príncipe, aproximadamente mil pessoas, seriam falantes do lung'le, trata-se de um dado superestimado, a não ser que se considere o conhecimento passivo da língua como critério. Agostinho (2015) afirma que há, em média, apenas 200 falantes de lung'le na Ilha do Príncipe, com diferentes níveis de competência linguística.

Além das variedades de português de São Tomé (PST) e português do Príncipe (PP), que consideramos neste trabalho como parte da macro-variedade de São Tomé e Príncipe 
(PSTP), e das línguas crioulas supracitadas, há também variedades reestruturadas de português, como o português dos Tongas e o português de Almoxarife (cf. FIGUEIREDO, 2008, 2009).

\section{O português falado na comunidade baiana de Helvécia}

Os colonizadores portugueses invadiram as terras, que hoje chamamos de Brasil, logo no início do século XVI, chegando, primeiramente, à região de Porto Seguro, no estado da Bahia (TAVARES, 2001). Durante o longo período da colonização portuguesa no Brasil (que durou de 1500 a 1822), a língua portuguesa esteve em contato com centenas de outras línguas tipologicamente diversas. Dentre elas, os primeiros contatos aconteceram com as línguas faladas pelas centenas de povos nativos que já habitavam o Brasil por vários séculos, por exemplo, línguas pertencentes às duas principais famílias linguísticas: MacroJê e Tupi (PETTER, 2007). Além das línguas referidas, o português europeu esteve em um intenso e longo contato com diversas línguas africanas, principalmente, as pertencentes às famílias linguísticas níger-congo (majoritariamente as línguas do grupo Bantu e Kwa) e afro-asiática (sendo a principal, Hauçá).

O contato linguístico entre o português europeu e as línguas africanas, mencionadas acima, se deu pelo fato de os portugueses terem usado o trabalho escravo de pessoas africanas sequestradas, por quase quatro séculos, fazendo com que a escravidão fosse parte da base econômica da colônia brasileira neste período (GOMES, 2019). De acordo com Tavares (2001), a importação de pessoas escravizadas para o Brasil se deu em quatro fases distintas, que são classificadas de acordo com as regiões do oeste africano nas quais o império brasileiro-português exercia o comércio escravo: I Ciclo da Guiné (século XVI); II Ciclo da Angola (século XVII); III Ciclo da Costa da Mina (séculos XVIII e XIX); IV Última fase (importações ilegais no final do século XIX).

Levando em consideração estas diferentes fases do tráfico de pessoas africanas escravizadas para o Brasil, o período que concerne à sócio-história de Helvécia é o do século XIX. Helvécia está localizada no extremo sul da Bahia e faz parte do Município de Nova Viçosa. A comunidade se situa em terras que, há mais de duzentos anos, faziam parte de um conjunto de plantações de café, denominada Colônia Leopoldina. Esta plantação, fundada em 1818 (CARMO, 2010), fazia parte de um conjunto de terras doadas pelo governo imperial do Brasil a imigrantes europeus (que integrava, em parte, um projeto de "embranquecimento" da população brasileira). Uma das condições destas "doações" era que os imigrantes não poderiam usar trabalho escravo, mas que deveriam eles mesmos trabalhar nas terras cedidas. Apesar disso, já em 1825, os europeus presentes na Colônia 
- Concordância de gênero variável em Português: aproximações entre variedades africanas e afro-brasileira

Leopoldina, em sua maioria suíços-alemães, começaram a comprar ilegalmente pessoas escravizadas para trabalhar nas suas imensas plantações de café. A produção de café no Brasil neste período estava crescendo, progressivamente, devido à revolução haitiana, que abriu o mercado cafeeiro para outros países como o Brasil.

Os colonos da Leopoldina compraram pessoas escravizadas ilegalmente até por volta de 1845, quando o tráfico foi proibido pela Lei Britânica de Aberdeen, que proibia a atividade. A Colônia existiu por quase 70 anos e teve seu pico econômico em 1848, quando grande parte da produção de café baiana era oriunda da Colônia Leopoldina. $\mathrm{O}$ seu fim se deu em 1888, ano que coincidiu com a abolição da escravatura no Brasil.

Em relação ao cenário linguístico da Colônia Leopoldina, muito ainda pode ser explorado, no entanto, alguns trabalhos acadêmicos (LUCCHESI; BAXTER; RIBEIRO, 2009; BAXTER; MELLO; SANTANA, 2014, entre outros) se propuseram a investigar as origens das pessoas escravizadas nesta localidade. De acordo com Lucchesi, Baxter e Ribeiro (2009), havia uma média de 10 pessoas escravizadas para 1 pessoa livre nas diversas plantações da Colônia. Já no que diz respeito aos números de pessoas escravizadas que foram importadas diretamente do continente africano, no Gráfico 2 podemos observar que este grupo formava quase a maioria de pessoas escravizadas na década de 1840. Essa porcentagem vai caindo com o passar dos anos, muito provavelmente pela proibição do tráfico escravo no Brasil, na época. Baxter, Mello e Santana (2014) possuem um dos escassos dados sobre os grupos linguísticos africanos mais consistentes nas plantações da Colônia, demonstrando que os falantes das línguas lorubá (referido como Nagô, na tabela) e as pertencentes ao grupo bantu eram os mais numerosos e consistentes na Colônia (ver Tabela 2).

Gráfico 2. Pessoas escravizadas africanas e brasileiras nas fazendas da Colônia Leopoldina

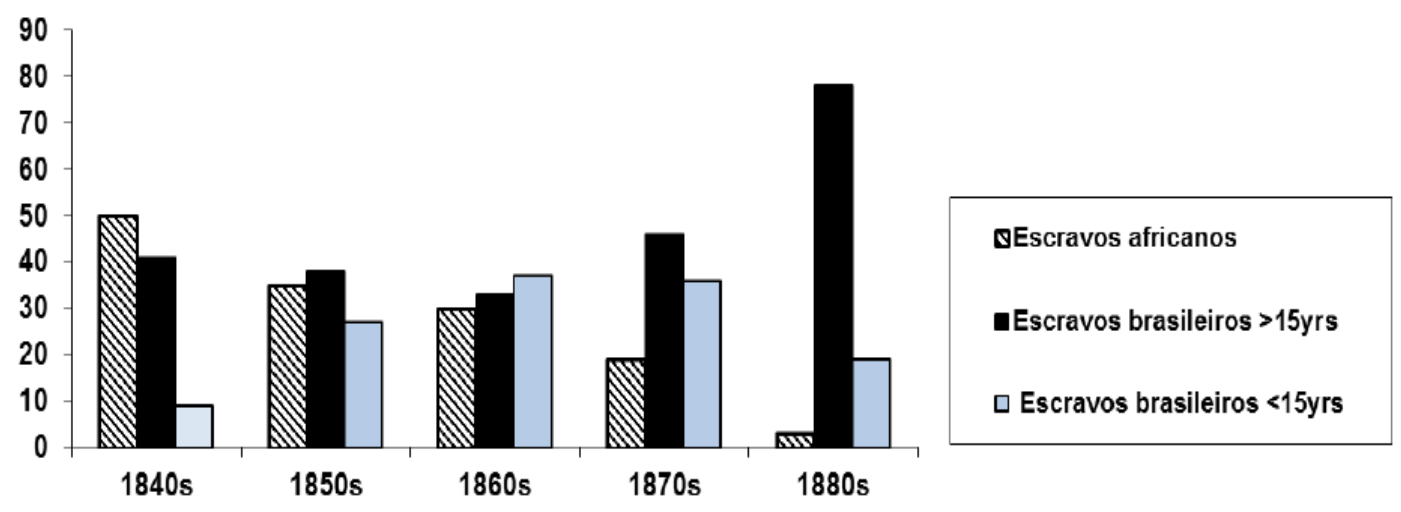

Fonte: Baxter, Mello e Santana (2014). 
Tabela 2. Origem das pessoas escravizadas africanas na Colônia Leopoldina entre 1847 e 1872

\begin{tabular}{rccc}
\hline 'ORIGEM' & 'grupo & $\begin{array}{c}\text { 5 roças da } \\
\text { Colônia Leopoldina }\end{array}$ \\
AFRICANA & linguístico' & $\mathbf{1 8 4 7 - 1 8 7 2}$ (Baxter 1999) \\
\hline Mina & NCNB & - & \\
Calabar & NCNB & 1 & \\
Tuãe & NCNB & 1 & \\
Tapa & NCNB & 2 & \\
Nagô & NCNB & 26 & $46 \%$ \\
Gêge & NCNB & 3 & \\
Benim & NCNB & 1 & \\
Aussá & CHÁDICO & 3 & \\
Rebôla & BANTU & 1 & \\
Rebolbo & BANTU & 1 & \\
Benguela & BANTU & 10 & \\
Congo & BANTU & 10 & \\
Cabinda & BANTU & 8 & \\
Moçambique & BANTU & 7 & \\
Angola & BANTU & 2 & \\
Cassange & BANTU & 1 & \\
Manjala & BANTU & 1 & \\
Monjolo & BANTU & 1 & \\
São Tomé & $?$ & 1 & \\
Não identificada & ???? & 14 & \\
\hline
\end{tabular}

Fonte: Baxter, Mello e Santana (2014).

Os dados de Helvécia usados neste artigo são oriundos de dois trabalhos de campo, um realizado por Lucchesi, Baxter e Ribeiro (2009) no início dos anos 1990, e outro feito por um dos autores do presente artigo em julho de 2019. Neste último trabalho de campo, a pesquisadora encontrou alguns vestígios da língua nagô (iorubá) em canções realizadas por alguns falantes idosos da comunidade (ver Quadro 1). Estas canções foram escutadas por três falantes nativos de iorubá, que puderam entendê-las parcialmente. 
- Concordância de gênero variável em Português: aproximações entre variedades africanas e afro-brasileira

Quadro 1. Canções em Nagô

\begin{tabular}{|c|c|}
\hline Falante/Idade & $\begin{array}{l}\text { Transcrição Fonética das } \\
\text { Canções em Nagô }\end{array}$ \\
\hline $\mathrm{H} 14 / 60$ & $\begin{array}{c}\text { [pa'pa ku ze fi'fa gwi kwa ke'do] } \\
\text { [pa'pa ku ze fi'fa gwi kwa] } \\
\text { [pa'pa ku зe Ji'fa gwi kwa] }\end{array}$ \\
\hline $\mathrm{H} 16 / 67$ & $\begin{array}{c}\text { [bo'lo bo'lo bo'lo ki nu kanu'ze } \Lambda^{\prime} z e \\
\text { [fa'ze a'ro a'ro co'mi ba'be] } \\
\text { ['bsmba ay'a bsmba ay'a] }\end{array}$ \\
\hline
\end{tabular}

Fonte: Lamberti (2021).

Por fim, os dados históricos e de campo apresentados acima, em conjunto com os apresentados por Lucchesi, Baxter e Ribeiro (2009) e Baxter, Mello e Santana (2014), nos demonstram dois principais aspectos sobre a situação histórico-linguística de Helvécia: que as línguas da família níger-congo eram majoritariamente faladas pelas pessoas africanas na Colônia Leopoldina e que, dentre elas, as línguas iorubá e diversas da família bantu eram as mais prevalentes.

\section{Metodologia}

Os dados analisados neste artigo foram obtidos a partir de trabalhos de campo realizados em Angola, em São Tomé e Príncipe e no Brasil. Em Angola, realizamos as coletas no Município do Libolo, Província de Cuanza Sul, Angola, em 2011 e 2013, no âmbito do Projeto ${ }^{6}$ que leva o mesmo nome do Município. Foram analisadas três entrevistas de informantes do sexo masculino (1) e feminino (2), dentro das faixas etárias de (13-20), (21-40) e (+60) anos, no momento da realização das coletas. Para a transcrição, seguem-se as orientações definidas em Santos (2015). Para São Tomé e Príncipe ${ }^{7}$, os dados foram coletados e transcritos ortograficamente por uma das autoras deste artigo a partir de quatro entrevistas sociolinguísticas realizadas durante trabalho de campo em

6 A equipe de estudos linguísticos realizou uma série de entrevistas sociolinguísticas, assim como registros informais de interlocução entre os libolenses, para compor o espólio do Projeto e parte do corpus para descrição e análise linguísticas. Os dados do Libolo são oriundos do espólio do "Projeto Libolo" - Centro de Investigação e Desenvolvimento (R\&DAO) da Universidade de Macau, sob o número de referência SRG011FSH13-CGF.

7 Por termos encontrado o fenômeno nas variedades das duas ilhas e por não estarmos fazendo uma análise quantitativa ou comparativa entre elas, consideramos aqui a macro-variedade do país (PSTP), conjunto das variedades de português de São Tomé (PST) e do Príncipe (PP). 
2013 e em 2016 (AGOSTINHO, 2013; AGOSTINHO; BALDUINO, 2016) com falantes do sexo feminino e masculino. Finalmente, para o Município baiano de Helvécia, os dados foram coletados através de entrevistas sociolinguísticas realizadas em dois momentos diferentes: em 1994 pelo projeto Vertentes (LUCCHESI; BAXTER; RIBEIRO, 2009) e em 2019 por uma das autoras deste artigo ${ }^{8}$. Para a transcrição, os dados seguem o padrão do grupo de pesquisa Vertentes. Foram analisados dados de três entrevistas sociolinguísticas, com dois falantes do sexo feminino (entrevistadas nos anos 90) e um do sexo masculino (entrevistado em 2019); todos tinham mais de 80 anos no momento das entrevistas. Cada entrevista durou cerca de uma hora.

Destacamos, também, que por mantermos as transcrições dos dados respeitando as versões originais das chaves de transcrição dos respectivos bancos de dados, não haverá conformidade nas transcrições dos dados dos três contextos aqui apresentados.

Após um recorte de parte do corpus das três variedades de português apresentadas, prosseguimos à descrição do material selecionado e destacamos as (não) realizações de concordância de gênero em cada uma delas. Observamos, então, os contextos em que aparecia o fenômeno em análise e buscamos sistematizá-los, conforme discutiremos a seguir.

Enfatizamos que o presente trabalho apresenta uma descrição preliminar do fenômeno de não concordância de gênero nas variedades analisadas, não apresentando, portanto, uma análise quantitativa dos dados, por se tratar de corpora obtidos a partir de metodologias de coleta diferentes com objetivos, a princípio, específicos, o que dificultaria uma análise quantitativa estatística na pesquisa em destaque.

\section{Discussão dos dados}

Nesta seção, traremos os dados da variedade do português falado no Município do Libolo, em São Tomé e Príncipe e na comunidade de Helvécia que apontam para a realização da não concordância de gênero no sintagma nominal e as análises que podem ser daí depreendidas. Antes, faremos uma breve retomada da literatura de alguns trabalhos que tratam da concordância em foco em diversas variedades da língua portuguesa, em especial, as variedades imersas em contato linguístico.

8 Os exemplos provenientes do Projeto Vertentes serão marcados como HEL-VER, e os coletados por uma das autoras deste artigo serão apresentados como HEL-19. 
- Concordância de gênero variável em Português: aproximações entre variedades africanas e afro-brasileira

Nossa hipótese é que a não concordância de gênero encontrada nos dados do Libolo, de São Tomé e Príncipe e de Helvécia é resultado do contato dessas variedades com línguas africanas e línguas crioulas, associado à reestruturação no aprendizado de L2 e de L1 com base em um modelo de L2 pelas primeiras gerações falantes de português nesses contextos a partir de uma transmissão do tipo bottleneck, em que alguns traços gramaticais são "regularizados" ou neutralizados (cf. BAKKER, 2014; GOOD, 2012, entre outros). Nesse sentido, dois dos traços comumente regularizados em processos de crioulização e de transmissão linguística irregular são o de concordância de número e gênero gramatical. Apesar do caráter descritivo e comparativo deste trabalho, enfatizamos que cada variedade tem uma gramática própria que é, portanto, diferente daquela do português padrão.

Primordialmente, exemplos de não concordância de gênero em determinantes e pronomes compõem a maior parte dos nossos dados, como podemos observar nos exemplos do PLB e do PSTP, a seguir. Na maioria dos casos, observamos o uso de modificadores masculinos como os, desses, esse e pouco com os substantivos femininos.

(5) não... é assim soba ele o meu irmão como vai a... a Lisboa e vai fazer as pesquisas na... no... no coisa ultramar... na biblioteca [PLB]

(6) então nesse... nesses pesquisa que os soba fazem [PLB]

(7) pra eles comemorarem uma grande uma grande feriado [PLB]

(8) Castigava quando encontra ali o pessoa [PLB]

(9) Não é? Assim aqui a- a- aquele tradição antigamente num mete sale [PLB]

(10) Lá em Luanda só tem lá as casas, chafarizes, a... o coiso, os árvore. Aqui então tem muitas palmeiras ma... palmeira, muitos folha tabaco, muitos pau [PLB]

(11) Ele lá... fazem brasas, trabalham, colhe os ca... cabra [...] O cabra é do se... do senhô do Cabibi [PLB]

(12) E agora eu tô com os netas [PSTP]

(13) Folha de mato, esses folhas que a gente faz calulu, bocadinho bocadinho desses folhas [...] porque ele é que corta a gente parir [PSTP]

(14) E: Mas aquela casa antiga a senhora chegou a ver?

I: Eu vi sim

E: Achou bonita?

I: [...] Esse já que o presidente fica nele [PSTP] 
(15) Ela é de Trindade, eu é de Santana, quando a gente é amiga com o outro, é que não toma homem de outro [PSTP]

$$
\text { Eu já tenho pouco sorte [PSTP] }
$$

Já nos casos de Helvécia, podemos constatar alguns exemplos em que a não concordância ocorre entre determinantes femininos, como $a$ e uma, com substantivos masculinos (17-18), além dos casos em que o oposto acontece, ou seja, o determinante masculino esse aparece com substantivos femininos (19-20).

(17) Com remédio, comprava purgante dava eles purgante, fazia a azeite de baga e dava purgante [HEL-VER]

(18) ocê pránta um prantinha, uma aimpim, uma batata, um milho, um fejão, você atira, né? [HEL-VER]

(19) É! Morreu. Esse gente de tempo, a maió parte tudo...[HEL-VER]

(20) Eu agradeço muito a Deus por esse passagem [HEL-19]

Outro contexto frequente nos nossos dados de uso de uma marca default, que seria o gênero masculino em PB e PE, é com pronomes resumptivos ou lembretes ${ }^{9}$. Nos exemplos (21-23) de São Tomé e Príncipe há o uso do pronome ele resumptivo fazendo referência a boneca, banana e casa; no exemplo (24) de Helvécia podemos observar o uso do pronome demonstrativo esse fazendo referência a terra; e, por fim, no exemplo (25) do Libolo temos o pronome dele que se refere ao substantivo feminino pessoa.

... boneca que a menina tava brincando com ele_[PSTP]

(23) E: Mas aquela casa antiga a senhora chegou a ver?

I: Eu vi sim

E: Achou bonita?

I: (...) Esse já que o presidente fica nele [PSTP]

\footnotetext{
9 Não há um consenso na literatura linguística sobre a definição de pronome lembrete, também referenciado como pronome resumptivo a depender do arcabouço teórico em consideração. Em geral, o pronome lembrete apresenta um caráter mais discursivo, relacionando-se com a noção de pronome-cópia em estruturas de tópico, ou é entendido como o pronome presente na formação de sentenças relativas resumptivas (ROCHA et al., 2011; ROCHA; RASO, 2013). Para o presente trabalho, foge de nosso escopo uma discussão acerca dessas peculiaridades, embora não ignoremos as diferenças e discussões inerentes a esse fato. Consideramos, assim, a noção de pronome lembrete para nossa análise, como um aspecto discursivo, nos termos de Pontes (1987 apud ROCHA; RASO, 2013, p. 40), em que esse pronome é correferente ao tópico sentencial.
} 
- Concordância de gênero variável em Português: aproximações entre variedades africanas e afro-brasileira

Verdadêra terra de nós é esse lá [HEL-VER]

(25) De cabrar é assim: a pessoa, se o marido dele morreu fica [PLB]

Contextos de particípio passado ou com adjetivos formados por particípio passado também apresentam marca morfológica de masculino para substantivos femininos, como pessoa, filha, carga, mãe, terra, bengala, menina e estrada podendo ser observados nos exemplos abaixo:

(26) Se uma pessoa está parado..._[PSTP]

(27) Até outra minha filha que tá parido... [PSTP]

(28) $\quad$...ou por carga pesado... [PSTP]

(29) ...pra pegar mãe com mão, se deixar maltratado, mãe também chegou na altura já não pode fazer nada. [PSTP]

(30) com essa terra destragado_[PSTP]

(31) essa... essa bengala é fabricado em Paquistão [PLB]

(32) A menina tá mei doentado, mas tá aí em casa. [HEL-VER]

(33) Essa estrada do boi aí todo asfaltado [HEL-19]

Já nos exemplos (34) do PLB e (35) de Helvécia, notamos o caso oposto no qual há marca morfológica de feminino nos particípios que acompanham substantivos masculinos como senhor e corpo:

(34) Fazia lá trabalho, vivia num senhor chamada Manoel Albino [PLB]

(35) E cipó dele era desses cipó grosso, dobrava que rochava em duas dobra, mas corpo da gente ficava_toda empoladinha_[HEL-VER]

A não concordância em contextos com o pronome $e u$, que faz referência a informantes do sexo feminino, também foi encontrada nos dados de São Tomé e Príncipe e Helvécia:

eles se revoltaram, porque eu é achado_[PSTP] ieu não lembra nada, poqu'eu tá pequeno, né? minha... meu pai morreu, eu pequeno. [HEL-VER]

(38) Meu irmão, quando saí daí, eu era casado, teve só essa Luiza [HEL-VER] 
leu? Não, senhô. Fui nascido ali na roça, ficô criô lá na roça, até dobrô, casô, tudo na roça. [HEL-VER]

Por fim, os exemplos a seguir apresentam casos de não concordância de gênero em adjetivos que modificam substantivos femininos em dados das três variedades investigadas neste artigo:



(42) Senhor disse um dia já mulher bebeu, tirou roupa, ficou nu [PSTP]

(43) tem porta de entrada... há uma rocha memo bem largo [PLB]

(44) Vai cavar a mandioca na lavra e casca descasca e mete $\mathrm{n}^{\prime}$ água, depois de ficar pronto estende [PLB]

(45) Afesta aí é bonito. Quand'eles faz, é bonito [HEL-VER]

(46) Eu gosto porque Helvécia é calmo [HEL-19]

Em suma, se combinarmos as análises de todos os dados aqui apresentados, podemos observar que as três variedades investigadas compartilham o traço de não concordância de gênero nos contextos em que há determinantes e pronomes seguidos de um substantivo, em pronomes resumptivos ou lembretes, em adjetivos formados por particípio passado e adjetivos masculinos que modificam substantivos femininos. É importante notar que, nestes contextos, o padrão mais comum que encontramos ocorre com marcadores masculinos que aparecem com substantivos femininos.

Desta maneira, podemos concluir que há um uso sistemático dos marcadores masculinos nas variedades investigadas aqui. Este comportamento foi também descrito por Figueiredo (2009) para o português de Almoxarife e de Helvécia. Por fim, a única característica que encontramos não ser compartilhada por todas as variedades é a não concordância de gênero do sintagma nominal quando o contexto traz o pronome eu com referência a falantes do sexo feminino, sendo este contexto encontrado somente nos exemplos provenientes de São Tomé e Príncipe e Helvécia. 
- Concordância de gênero variável em Português: aproximações entre variedades africanas e afro-brasileira

Línguas do grupo níger-congo, que inclui línguas bantu, edóides e kwa, não possuem marcação de gênero baseada em sexo, sendo as distinções 'masculino' e 'feminino' irrelevantes (HEINE; NURSE, 2007). Como mencionado acima, o português do Libolo permanece em contato com línguas do grupo bantu, principalmente o quimbundu. As línguas crioulas do Golfo da Guiné, como já apontado, possuem substrato edóide, além da influência adstratal bantu. No caso de São Tomé e Príncipe, as primeiras gerações de falantes de português eram falantes nativos das línguas crioulas do país. Atualmente, a língua portuguesa permanece em contato com línguas crioulas, apesar do crescente abandono das línguas nacionais (ARAUJO; AGOSTINHO, 2010) Em Helvécia, o português esteve em contato com línguas bantu e kwa entre no século XIX. Assim, os três contextos analisados neste artigo apresentavam ou apresentam contato com línguas da mesma macro-família.

Apesar disso, é válido ressaltar que o fenômeno estudado aqui não se comporta de maneira idêntica nas variedades pesquisadas. Isso se dá porque, apesar de serem contextos que apresentam algumas similaridades, fatores como o nível de bilinguismo, a história social e a duração do contato, e as diferentes dinâmicas de poder existentes em cada comunidade de fala diferem (WINFORD, 2013), fazendo que a frequência e extensão da não marcação de gênero em cada variedade sejam distintas. Assim, apesar de não observarmos exatamente os mesmos fatores sociais na formação de cada uma destas variedades, alguns fatores (sócio)linguísticos envolvidos neste processo são semelhantes, sendo que os indivíduos que adquiriram português nestes contextos eram falantes nativos de línguas tipologicamente semelhantes, além do fato de que essas línguas não eram variedades de prestígio. Sendo assim, acreditamos que, em virtude disso, podemos observar a não concordância de gênero nas três variedades.

Além disso, é comum a perda das marcas flexionais através das quais se realizam as concordâncias de número e de gênero em processos de crioulização (MCWHORTER, 2001; HOLM, 2004; CROWLEY, 2008; LUCCHESI, 2009). Nas línguas crioulas do Golfo da Guiné, por exemplo, os nomes e determinantes não se flexionam morfologicamente quanto a gênero, e a distinção do sexo entre seres animados é marcada pelos adjetivos macho/fêmea. Assim, os dados aqui apresentados estão de acordo com nosso pressuposto inicial, de que fatores sociais comuns em um ambiente de contato podem gerar resultados linguísticos similares (cf. YAKPO, 2020), o que indica que a variação e mudança linguísticas estão relacionadas com fatores sociais e que o contato linguístico é um desses fatores. 


\section{Considerações finais}

Este artigo apresentou dados de concordância variável de gênero em três variedades de português em contato: Libolo, São Tomé e Príncipe e Helvécia. Observamos que as três variedades não apresentam concordância em contextos similares, tais como, determinantes, pronomes, pronomes lembrete, substantivos/adjetivos e adjetivos formados por particípio passado. Em todos os casos de não concordância encontrados, o uso de uma marca gramatical default, o que corresponderia ao gênero "masculino" em PB e PE, foi utilizado, como já era esperado (cf. FIGUEIREDO, 2009; LUCCHESI; BAXTER; RIBEIRO, 2009). Assim, observamos que, nas variedades analisadas, a concordância de gênero difere da norma padrão do português, apontando para o caráter variável e para a possibilidade de não realização do fenômeno nas três variedades.

A presente comparação parece corroborar nossa hipótese de que a não concordância de gênero nessas variedades é resultado do contato linguístico com línguas africanas do grupo níger-congo, que não possuem marcação morfológica de gênero relacionada a sexo, além do aprendizado de L1 a partir de um modelo de L2 que passa por uma transmissão do tipo bottleneck. Nesse sentido, a literatura sobre línguas crioulas e de contato oferece evidências suficientes para afirmarmos que fatores sociais em combinação com fatores linguísticos formam a gramática das variedades que são resultado do contato linguístico (cf. WINFORD, 2013).

Como apresentado anteriormente, a não distinção da marcação de gênero na macro-família níger-congo pode ter sido imposta na aquisição do traço gênero, quando os falantes nativos dessas línguas estavam em processo de aquisição do português. Assim, nossos dados indicam que variação e mudança linguísticas estão associadas a fatores sociais, além de corroborar a ideia de que contextos sociais similares podem gerar resultados linguísticos similares.

\section{Referências}

AGOSTINHO, A. L. External vowel sandhi processes in lung'le considering stress and tone. Working papers em linguística, v. 20, p. 74-92, 2019.

AGOSTINHO, A. L. Fonologia do lung'le. München: LINCOM, 2016.

AGOSTINHO, A. L. Fonologia e método pedagógico do lung'le. 2014. Tese (Doutorado em Filologia e Língua Portuguesa) - Faculdade de Filosofia, Letras e Ciências Humanas, Universidade de São Paulo, São Paulo, 2015. 
- Concordância de gênero variável em Português: aproximações entre variedades africanas e afro-brasileira

AGOSTINHO, A. L. Trabalho de campo em São Tomé e Príncipe. 2013. Inédito.

AGOSTINHO, A. L.; ARAUJO, G.; SANTOS, E. F. Interrogative particle and phrasal pitchaccent in polar questions in Fa d'Ambô. Boletim do Museu Paraense Emílio Goeldi. Ciências humanas, v. 14, p. 857-872, 2019.

AGOSTINHO, A. L.; BALDUINO, A. Trabalho de campo em São Tomé e Príncipe. 2016. Inédito.

AGOSTINHO, A. L.; BANDEIRA, M.; ARAUJO, G. A. O lung'le na educação escolar de São Tomé e Príncipe. Trabalhos em Linguística Aplicada, Campinas, v. 55, n. 3, p. 591-618, 2016.

ARAUJO, G. A.; AGOSTINHO, A. L.; SILVEIRA, A. C.; FREITAS, S.; BANDEIRA, M. Fa d'Ambô: Língua crioula de Ano Bom. Cadernos de Estudos Linguísticos, Campinas, São Paulo, v. 55, n. 2, p. 25-44, 2013.

ARAUJO, G. A.; AGOSTINHO, A. L. Padronização das línguas nacionais de São Tomé e Príncipe. Língua e Instrumentos Linguísticos, v. 26, p. 49, 2010.

BAKKER, P. Creoles and typology: Problems of sampling and definition. Journal of Pidgin and Creole Languages, v. 29, n. 2, p. 437-455, 2014.

BALDUINO, A. M. A nasalidade no português de STP. 2018. Dissertação (Mestrado em Filologia e Língua Portuguesa) - Faculdade de Filosofia, Letras e Ciências Humanas, Universidade de São Paulo, São Paulo, 2018.

BANDEIRA, M. Reconstrução fonológica e lexical do protocrioulo do Golfo da Guiné. 2017. Tese (Doutorado em Filologia e Língua Portuguesa) - Faculdade de Filosofia, Letras e Ciências Humanas, Universidade de São Paulo, São Paulo, 2017.

BAXTER, A.; MELLO, C. F.; SANTANA, N. G. A. A construção de objeto duplo e as influências do substrato no português afrobrasileiro (e africano). PAPIA, v. 24, p. 283-306, 2014.

BAXTER, A. A concordância de número. In: LUCCHESI, D. et al. (org.). O português afrobrasileiro. Salvador: EdUFBA, 2009. p. 269-293. 
BIRMINGHAM, D. A conquista portuguesa de Angola. Porto: A Regra do Jogo, 1974.

BRANDÃO, S. F. Concordância nominal no português de São Tomé e no português de Moçambique. In: BRANDÃO, S. F. (org.). Duas variedades africanas do português: variáveis fonético-fonológicas e morfossintáticas. São Paulo: Blucher, 2018. p. 203-244.

BRANDÃO, S. F. Concordância nominal. In: VIEIRA, S. R.; BRANDÃO, S. F. (org.). Ensino de Gramática: descrição e uso. 2. ed. São Paulo: Contexto, 2016. p. 57-83.

BRANDÃO, S. F.; VIEIRA, S. R. Concordância nominal e verbal: contribuições para o debate sobre o estatuto da variação em três variedades urbanas do português. Alfa, São Paulo, v. 53, n. 3, p. 1035-1064, 2012.

CALDEIRA, A. M. Tráfico de escravos e conflitualidade. O arquipélago de São Tomé e Príncipe e o reino do Congo durante o século XVI. Revista Ciências e Letras, [S. I.], v. 44, p. 55-76, 2008.

CARDOSO, M. Cabo Verde e S. Tomé e Príncipe. Porto: IPAD, 2007.

CARMO, A. F. Colonização e Escravidão na Bahia: a Colônia Leopoldina (1850-1888). 2010. Dissertação (Mestrado em História) - Universidade Federal da Bahia, Salvador, 2010.

CASTRO, P. P. As construções interrogativas, de tópico e de foco na língua crioula de Guiné-Bissau. 2013. Dissertação (Mestrado em Linguística) - Universidade Federal do Rio do Janeiro, Rio de Janeiro, 2013.

CROWLEY, T. Pidgin and creole morphology. In: KOUWENBERG, S.; SINGLER, J. V. (ed.). The Handbook of Pidgin and Creole Studies. Oxford: Wiley-Blackwell, 2008. p. 74-97.

CRYSTAL, D. Language Death. Cambridge: Cambridge University Press, 2000.

FERRAZ, L. The Creole of São Tomé. Johannesburg: Witwatersrand University Press, 1979.

FIGUEIREDO, C. F. G. Aspectos histórico-culturais e sociolinguísticos do Libolo: aproximações com o Brasil. In: OLIVEIRA, M. S. D.; ARAUJO, G. A. (org.). O Português na África Atlântica: Angola, Cabo Verde, Guiné Bissau, São Tomé e Príncipe. São Paulo: FFLCH/USP/Humanitas, 2018. p. 47-97. 
- Concordância de gênero variável em Português: aproximações entre variedades africanas e afro-brasileira

FIGUEIREDO, C. F. G. A concordância plural variável no sintagma nominal do português reestruturado da comunidade de Almoxarife, São Tomé (Desenvolvimento das regras de concordância variáveis no processo de transmissão-aquisição geracional). 2010. Tese (Doutorado em Linguística) - Faculdade de Ciências Sociais e Humanas, Macau, 2010.

FIGUEIREDO, C. F. G. A configuração do SN plural do português reestruturado de Almoxarife - S. Tomé Carlos. Revista de Crioulos de Base Lexical Portuguesa e Espanhola, [S.I.], v. 1, n. 1, p. 28-55, 2009.

FIGUEIREDO, C. F. G. A concordância variável no sintagma nominal plural do português reestruturado de Almoxarife (São Tomé). PAPIA, [S. I.], v. 18, n. 1, p. 23-43, 2008.

FIGUEIREDO, C. F. G.; OLIVEIRA, M. S. D. Português do Município do Libolo Angola, e português étnico da comunidade de Jurussaca Brasil cotejando os sistemas de pronominalização. PAPIA, v. 2., n. 23, p. 105-185, 2013.

FIGUEIREDO, C. F. G.; SANTOS, E. F. Construções [FOC + QUE]: português do Município do Libolo, Kwanza Sul, Angola. Encontro Conjunto do XIV Congresso Anual da ACBLPE (Associação de Crioulos de Base Portuguesa e Espanhola) com o Congresso de Verão de 2013 da SPCL (Society for Pidgin and Creole Linguistics) - Faculdade de Letras, Universidade de Lisboa, Lisboa, Portugal, 2013. [Manuscrito]

GOMES, L. Escravidão: do primeiro leilão de cativos em Portugal ate a morte de Zumbi dos Palmares. v. 1. São Paulo: Editora Globo, 2019.

GOOD, J. Typologizing grammatical complexities. Journal of Pidgin and Creole Languages, v. 27, n. 1, p. 47-93, 2012.

GÜNTHER, W. Das portugiesische Kreolisch der Ilha do Príncipe. Marburg an der Lahn: Im Selbstverlag, 1973.

HAGEMEIJER, T. The Gulf of Guinea Creoles: Genetic and Typological Relations. Journal of Pidgin and Creole Languages, Amsterdam, v. 26, n. 1, p. 111-154, 2011.

HAGEMEIJER, T. As línguas de S. Tomé e Príncipe. Revista de Crioulos de Base Lexical Portuguesa e Espanhola, Lisboa, v. 1, n. 1, p. 1-27, 2009. 
HEINE, B.; NURSE, D. A linguistic geography of Africa. Cambridge: Cambridge University Press, 2007.

HERNANDEZ, L. A África na sala de aula. 2. ed. rev. São Paulo: Selo Negro, 2008.

HOLM, J. An Introduction to Pidgins and Creoles. Cambridge: Cambridge University Press, 2004.

INVERNO, L. A transição de Angola para o português vernáculo: estudo morfossintático do sintagma nominal. In: CARVALHO, A. M. (org.). Português em contato. Madrid/ Frankfurt: Iberoamericana, Editorial Vervuert, 2009. p. 87-106.

INVERNO, L. Português vernáculo do Brasil e português vernáculo de Angola: reestruturação parcial vs. mudança linguística. In: ENCUENTRO DE ACBLPE, 3, 2003, Coruña. Actas del III encuentro de ACBLPE, Madrid: Iberoamericana: Vervuert, 2004. p. 201-213.

LADHAMS, J. Article agglutination and the African contribution to the Portuguese-based Creoles. In: BARTENS, A.; BAKER, P. (ed.). Black through White. London: Battlebridgde, 2012. p. 31-50.

LAMBERTI, L. Language Ideologies in Afro-Brazilian Portuguese. Studies in Hispanic and Lusophone Linguistics. 2021. No prelo.

LIPSKI, J. M. El dialecto afroyungueño de Bolivia: en busca de las raíces del habla afrohispánica. Revista Internacional de Lingüística Iberoamericana, v. 4, n. 2, p. 137-166, 2006.

LUCCHESI, D.; BAXTER, A.; RIBEIRO, I. O português afro-brasileiro. Salvador: EdUFBA, 2009.

LUCCHESI, D. A concordância de gênero. In: LUCCHESI, D.; BAXTER, A.; RIBEIRO, I. (org.). O português afro-brasileiro. Salvador: EdUFBA, 2009. p. 295-318.

MAURER, P. Principense (Lung'le). London: Battlebridge Publications, 2009.

MCWHORTER, J. H. The world's simplest grammars are creole grammars. Linguistic Typology, v. 5, n. 2, p. 125-166, 2001. 
- Concordância de gênero variável em Português: aproximações entre variedades africanas e afro-brasileira

MIGUEL, M. H. A língua portuguesa em Angola: normativismo e glotopolítica. Lucere, $\mathrm{n}$. 5, p. 35-48, 2008.

MIGUEL, M. H. Dinâmica da pronominalização no português de Luanda. Luanda: Editorial Nzila, 2003.

MINGAS, A. A Interferência do kimbundu no português falado em Lwanda. Porto: Campo das Letras, 2000.

PELISSIER, R. Histórias das campanhas de Angola: resistência e revoltas (1845-1941), v. 1 e 2. Lisboa: Editora Estampa, 1997.

PETTER, M. M. T. Aspectos morfossintáticos comuns ao português angolano, brasileiro e moçambicano. PAPIA, n. 19, p. 201-220, 2009.

PETTER, M. M. T. Variedades linguísticas em contato: português angolano, português brasileiro, português moçambicano. 2008. Tese (Livre docência) - Departamento de Linguística, Universidade de São Paulo, 2008.

PETTER, M. M. T. Línguas africanas no Brasil. África: Revista do Centro de Estudos Africanos, v. 27-28, p. 63-89, 2007.

PINTA, J. Gender Agreement in Correntino Spanish. Journal of Language Contact, 2021. [No prelo]

REDINHA, J. Etnias e culturas de Angola. Coimbra: AULP, 2009.

ROCHA, B.; RASO, T. O pronome lembrete e a Teoria da Língua em Ato: uma análise baseada em corpora. Veredas, v. 17, n. 2, p. 39-59, 2013.

ROCHA, B. et al. O pronome lembrete e a Teoria da Língua em Ato: novas perspectivas de análise. In: COLÓQUIO BRASILEIRO DE PROSÓDIA DA FALA, 3, 2011, Belo Horizonte. Anais do Colóquio Brasileiro de Prosódia da Fala, v. 1, 2011.

SANTIAGO, A. M.; AGOSTINHO, A. L. Situação linguística do português em São Tomé e Príncipe. A Cor Das Letras, v. 21, n. 1, p. 39-61, 2020. 
SANTOS, E. F. Aspectos da língua portuguesa em Angola. PAPIA, v. 28, n. 1, p. 25-49, 2018.

SANTOS, E. F. Sentenças marcadas para o foco no português do Libolo: uma proposta de análise derivacional. 2015. Tese (Doutorado) - Faculdade de Filosofia, Letras e Ciências Humanas, Universidade de São Paulo, São Paulo, 2015.

SÁNCHEZ, L. Word order, predication and agreement in DPs in Spanish, Southern Quechua and Southern Andean bilingual Spanish. In: ZAGONA, K. (ed.). Grammatical Theory and Romance Languages: Selected Papers from the 25th Linguistic Symposium on Romance Languages. Amsterdam: John Benjamins Publishing Company, 1996. p. 209-218.

SCHUCHARDT, H. Beiträge zur Kenntnis des kreolischen Romanisch. Zum Negerportugiesischen der Ilha do Principe. Zeitschrift für Romanische Philologie, Saarbrücken, v. 13, p. 461-475, 1889.

SEDRINS, A. P.; SILVA, C. R. T. Padrões de concordância de gênero e número no sintagma nominal em variedades africanas do português. Revista Leitura, Maceió, v. 2, n. 59, p. 85-105, 2017.

SEIBERT, G. Crioulização em Cabo Verde e São Tomé e Príncipe: divergências históricas e identitárias. Afro-Ásia, [S. I.], v. 49, p. 41-70, 2014.

SEIBERT, G. São Tomé and Príncipe: The first plantation economy in the tropics. In: LAW, R.; SCHWARZ, S.; STRICKRODT, S. (ed.). Commercial Agriculture, the Slave Trade and Slavery in Atlantic Africa. Suffolk: Boydell \& Brewer, 2013. p. 54-78.

TAVARES, L. H. D. História da Bahia. EdUFBA/UNESP, 2001.

THOMASON, S.; KAUFMAN, T. Language Contact, Creolization, and Genetic Linguistics. Berkeley: University of California Press, 1988.

VALKHOFF, M. F. Studies in Portuguese and Creole. Johannesburg: Witwatersrand University Press, 1966.

WINFORD, D. Social factors in contact languages. In: BAKKER, P.; MATRAS, Y. Contact languages: a comprehensive guide. De Gruyter, 2013. p. 363-416. 
- Concordância de gênero variável em Português: aproximações entre variedades africanas e afro-brasileira

YAKPO, K. Social Factors. In: ADAMOU, E.; MATRAS, Y. (ed.). The Routledge Handbook of Language Contact. London: Routledge, 2020. p. 129-146.

COMO CITAR ESTE ARTIGO: AGOSTINHO, Ana Lívia; LAMBERTI, Luana; SANTOS, Eduardo Ferreira dos. Concordância de gênero variável em Português: aproximações entre variedades africanas e afro-brasileira. Revista do GEL, v. 18, n. 3, p. 40-69, 2021. Disponível em: https://revistadogel.gel.org.br/

Submetido em: 31/08/2021 | Aceito em: 18/10/2021. 